\title{
RodRIGo CÉSAR DE MENEZES E O PAPEL DA METRÓPOLE NA INCORPORAÇÃO DAS MINAS DE CUIABÁ À AMÉRICA PORTUGUESA (1721 - 1728)
}

\author{
Luis Henrique Menezes Fernandes*
}

Resumo: A historiografia brasileira concebeu tradicionalmente a dilatação das fronteiras da capitania de São Paulo como resultado direto da ação dos bandeirantes, minimizando ou mesmo negando o papel da metrópole nesse processo. De modo distinto, concluímos, através da análise das fontes relativas ao governo do capitão Rodrigo César de Menezes (1721 - 1728), a existência de uma importante ação metropolitana nesse processo, sobretudo relacionada à incorporação das recémdescobertas minas de Cuiabá à América portuguesa.

Palavras-chave: capitania de São Paulo; minas de Cuiabá; ação metropolitana.

Abstract: The brazilian historiography traditionally conceived the extending the São Paulo's capitainship frontiers as a direct result of "bandeirantes" action, minimizing or even denying the role of the metropolis in this process. Differently, we conclude, by examining the sources for the government of captain Rodrigo César de Menezes (1721 - 1728), the existence of a important metropolitan action in this process, mainly related to the incorporation of the newly discovered mines of Cuiabá to the portuguese America.

Key-words: São Paulo's capitainship; mines of Cuiabá; metropolitan action.

* Mestrando do Programa de Pós-Graduação em História,UNESP (Faculdade de Ciências e Letras de Assis). 
|176 |

Rodrigo César de Menezes e o papel da metrópole na ...

Este artigo tem por objetivo avaliar o papel da metrópole no processo de dilatação das fronteiras da capitania de São Paulo, durante o governo do capitão-general Rodrigo César de Menezes. A relevância dessa conjuntura espaço-temporal para a compreensão do objeto proposto está relacionada aos significativos descobrimentos auríferos, realizados por sertanistas paulistas, no interior do continente, e a posterior incorporação dessas "novas" regiões aos domínios portugueses na América. Trata-se, portanto, de uma exposição sobre a ação metropolitana na expansão dos domínios portugueses na América em princípios do século XVIII, tema este tradicionalmente tributário da história das bandeiras paulistas.

Rodrigo César de Menezes tomou posse do cargo de governador da capitania de São Paulo em 6 de setembro de 1721, perante o Senado da Câmara de São Paulo, no qual permaneceu até 1728. Era membro de uma família da qual saíram importantes autoridades do vasto Império português. Seu pai, Luís César de Menezes, fora governador do Rio de Janeiro, de Angola e posteriormente governador-geral do Brasil. Durante o período em que esteve encarregado do governo da capitania de São Paulo, seu irmão mais velho, Vasco Fernandes César de Menezes, primeiro Conde de Sabugosa, ocupava o cargo de vice-rei do Brasil, com o qual trocou abundante correspondência. É importante mencionar também que, após o término de seu serviço na capitania de São Paulo, Rodrigo César de Menezes foi também governador de Angola de 1732 a 1738, ano em que faleceu, em sua viagem de volta para o Rio de Janeiro.

Há algumas razões que fazem do governo de Rodrigo César de Menezes um objeto de estudo importante para a compreensão do papel da metrópole na expansão dos domínios portugueses aos sertões longínquos da América. Em primeiro lugar, devemos esclarecer que Rodrigo César foi o primeiro governador da capitania de São Paulo após o desmembramento de Minas Gerais em 1720, após recomendações do Conselho Ultramarino. Essa reorganização administrativa esteve diretamente vinculada ao descobrimento das minas do Cuiabá, ocorrido em torno de 1718, 
por sertanistas paulistas comandados por Pascoal Moreira Cabral, os quais encontraram o precioso metal na região mais central da América do Sul e, portanto, muito além do meridiano proposto pelo Tratado de Tordesilhas (1494). Como sabemos, essa linha imaginária deveria delimitar as possessões portuguesas e castelhanas na América, muito embora na prática não fosse respeitada, tanto pela sua caducidade como pela dificuldade em reconhecer sua exata localização. Assim, a nomeação de Rodrigo César de Menezes ao cargo de governador da nova capitania de São Paulo vincula-se a essa conjuntura de descobrimentos auríferos em regiões de soberania duvidosa.

Além disso, em 1725 foram descobertas outras importantes jazidas de ouro no interior do continente, desta vez pelo bandeirante Bartolomeu Bueno da Silva - o segundo Anhanguera -, o qual organizou uma expedição oficial, regimentada pelo próprio governador, rumo aos "sertões dos Guayazes" (Goiás). Por fim, não podemos esquecer de que a terceira década do século XVIII na América portuguesa foi um dos períodos mais promissores da economia mineradora, tanto pela ascendência dos lucros proporcionados pelas Minas Gerais, como pelo surgimento de novos centros proeminentes de extração aurífera na América, durante o reinado de D. João V em Portugal (1706 - 1750), considerado como o período de maior ostentação da corte portuguesa em toda a sua história.

A maneira como foram anexadas ao domínio português as regiões mineradoras de Cuiabá e Goiás, e o papel da ação metropolitana nesse empreendimento, pode ser exemplar para uma compreensão mais genérica do processo que efetivou a dilatação dos domínios lusitanos em toda a América, através da exploração das riquezas proporcionadas pelas distintas capitanias. Não devemos nos esquecer, porém, que uma das fundamentais habilidades do historiador consiste na cautela das suas afirmações, pois deve-se buscar um equilíbrio perfeito entre as generalizações e as especificidades, equilíbrio dificilmente encontrado. Houve, obviamente, especificidades relacionadas às diferentes conjunturas encontradas pelo Império português no processo de incorporação 
|178|

Rodrigo César de Menezes e o papel da metrópole na ...

de territórios americanos aos seus domínios, mas o papel da metrópole nas diferentes situações pode ser equivalente por causa da aparente recorrência dos instrumentos utilizados.

No período analisado, expandiam-se as possibilidades de enriquecimento no interior do território americano, tanto para a metrópole como para os colonos, sobretudo nos sertões auríferos de Cuiabá e Goiás que iam sendo revelados. Por esse motivo, era conveniente que a monarquia portuguesa dilatasse o seu domínio e governança a regiões tão distantes quanto promissoras. Vivia-se um momento de grandes expectativas quanto às explorações auríferas na América portuguesa, e era mister que a Coroa portuguesa assegurasse a governabilidade e a defesa da sua colônia. De acordo com a nossa hipótese inicial, o que garantiu a incorporação das regiões das minas de Cuiabá e Goiás ao Império português, concomitantemente e em harmonia expansão bandeirante paulista, foi a ação do próprio Estado metropolitano em busca de interesses definidos, cuja realização culminou na dilatação territorial da América portuguesa. Sendo assim, supomos que a Coroa portuguesa não entregou a tarefa de ocupação desses espaços exclusivamente à iniciativa privada, mas que o processo de dilatação das fronteiras da capitania de São Paulo, no período analisado, ocorreu como resultado, em grande medida, de uma política de ocupação idealizada e praticada pela metrópole.

No entanto, privilegiaremos neste artigo o processo de incorporação das minas de Cuiabá aos domínios lusitanos, em detrimento da ação da metrópole sobre os sertões de Goiás. Esse aparente desequilíbrio pode ser explicado pelo fato de que o grande assunto de toda a documentação referente ao governo de Rodrigo César de Menezes na capitania de São Paulo são as minas de Cuiabá. Enquanto estas se encontravam em crescente processo de exploração, Goiás ainda estava em fase de descobrimento e as demais regiões eram relativamente ofuscadas diante da proeminente riqueza que se vislumbrava nos sertões cuiabanos. Desse modo, centralizaremos nossa análise em avaliar o papel da metrópole na incorporação das minas de Cuiabá ao domínio efetivo da Coroa lusitana. 
A historiografia brasileira, de modo geral, compreendeu tradicionalmente o processo de formação territorial do Brasil como resultado direto e exclusivo da ação particular dos bandeirantes paulistas nos sertões longínquos da América. Essa interpretação estabeleceu um rígido vínculo entre a exploração dos sertões pelas bandeiras e a dilatação das fronteiras da América portuguesa. No entanto, supomos que existiram outros aspectos fundamentais que contribuíram para a formação histórica do território nacional, como a própria ação metropolitana, mas que acabaram ignorados ou minimizados por essa interpretação dominante, subsidiária da historiografia paulista.

A exploração dos sertões da América pelos bandeirantes poderia muito bem não ter acarretado a sua anexação aos domínios lusitanos - como muitas vezes de fato aconteceu -, embora não possamos deixar de reconhecer que tenha sido um aspecto fundamental. Além dos descobrimentos realizados pelos sertanistas paulistas nas regiões localizadas a oeste do meridiano de Tordesilhas, como os próprios sertões de Cuiabá e Goiás, deve também ser considerado essencial, para a efetiva anexação desses espaços à América portuguesa, o papel da ocupação política e econômica realizada nesses rincões pela metrópole portuguesa e pelos seus prepostos residentes na América. A ocupação política e econômica, neste caso, se fez, por um lado, através da expansão da governabilidade metropolitana ao interior do continente, através da formação de estruturas administrativas, militares e fiscais e, por outro, pela organização da produção, do abastecimento interno e da comunicação nas regiões que se desejava incorporar. Neste sentido, o papel da metrópole nesse processo parece ter sido crucial para a bem sucedida anexação desses espaços aos domínios portugueses. Entretanto, a historiografia brasileira herdou de seus intelectuais mais proeminentes que se dedicaram a essa temática uma perspectiva bastante contraditória com relação à hipótese que confere à metrópole uma importância significativa nesse fenômeno. ${ }^{1}$

${ }^{1}$ Principalmente Affonso de E. Taunay, Basílio de Magalhães e Washington Luís. 
| $180 \mid$

Rodrigo César de Menezes e o papel da metrópole na ...

Além de entrar em conflito a tradição historiográfica paulista, a proposta de estudar as diretrizes de uma política metropolitana de expansão territorial encontra-se em grave contradição com o trabalho de Sérgio Buarque de Holanda sobre o semeador e o ladrilhador, no livro Raizes do Brasil (Holanda, 1956). Como sustentar a existência dessa política diante da afirmação de que Portugal preferia "agir por experiências sucessivas, nem sempre coordenadas umas às outras, a traçar de antemão um plano para seguilo até o fim"? (p. 151). Considerando a empresa colonizadora portuguesa como tateante e negligente, este pensador afirma sobre a construção das suas cidades coloniais que não houve "nenhum rigor, nenhum método, nenhuma previdência, sempre esse significativo abandono que exprime a palavra 'desleixo' [...], [como] convicção de que não vale a pena" (p. 152). De acordo com essas afirmações, a dilatação das fronteiras da América portuguesa não pode ser compreendida como resultado de uma política metropolitana de ocupação, mas como consequência unicamente da ação particular dos bandeirantes paulistas.

Não obstante essas afirmações, parece-nos inegável a existência de, quando não uma política muito bem ordenada, ao menos um propósito de ocupação, sobretudo no período dos descobrimentos auríferos em Cuiabá e Goiás, ainda que suas diretrizes se mostrem de maneira implícita e fragmentada na documentação. O autor de Raízes do Brasil também afirma que "os paulistas, graças a sua energia e ambição, tinham corrigido por conta própria o traçado de Tordesilhas, estendendo a colônia sertão a dentro". (p. 135) Essa afirmação corresponde à supracitada tendência historiográfica paulista, que heroifica o bandeirante como construtor exclusivo do território nacional. Os sertanistas podem ter explorado imensos territórios por conta própria - ou seja, sem o auxílio direto da Fazenda Real -, mas, como já foi dito, a dilatação de um território não se faz somente com a sua exploração.

A noção de que a metrópole não exerceu papel significativo na expansão das fronteiras luso-americanas está relacionada à verdade de que a maioria das expedições sertanistas foram 
custeadas por particulares paulistas, sendo essa uma das justificativas capitais para se considerar os bandeirantes como os únicos responsáveis pela formação territorial do Brasil. No entanto, seria inimaginável que a Fazenda Real financiasse todas as expedições sertanistas, quando estas eram em grande parte, sobretudo nos séculos XVI e XVII, destinadas à escravidão indígena ilegal. Para que a linha de Tordesilhas fosse efetivamente "corrigida", a metrópole pode não ter financiado diretamente as expedições sertanistas, mas provavelmente exerceu o seu poder através de outras ferramentas para fazê-lo. Desse modo, se a metrópole de fato exerceu um papel fundamental no processo de incorporação de Cuiabá e Goiás à América portuguesa, como tencionamos demonstrar, algumas das assertivas basilares de Sérgio Buarque de Holanda precisarão ser relativizadas.

O próprio Sérgio Buarque de Holanda assegura que "acabadas as expedições, quando não acabavam mal, tornavam eles [os bandeirantes] geralmente à sua vila e aos seus sítios da roça. E assim, antes do descobrimento das minas, não realizaram obra colonizadora, salvo esporadicamente" (p. 137). Essa afirmação sugere que a expansão territorial dos limites da América portuguesa não dependeu apenas da ação sertanista, mas também de outros fatores essenciais, ligados aos descobrimentos auríferos, dentre os quais pretendemos destacar a ação metropolitana. Sobre a nova conjuntura econômica do século XVIII, Sérgio Buarque de Holanda afirma que:

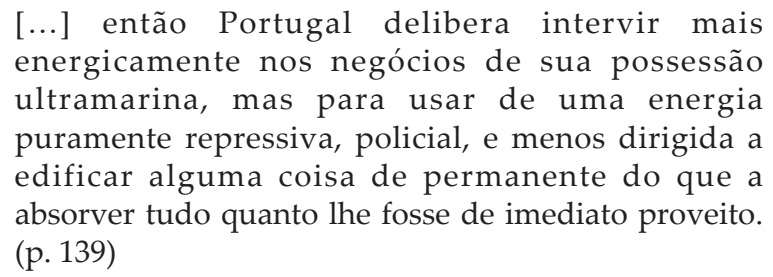

Desse modo, o próprio autor relativiza suas próprias generalizações, sem contudo creditar importância alguma à metrópole no tocante à dilatação territorial. Fica claro, porém, 
| 182 |

Rodrigo César de Menezes e o papel da metrópole na ...

que eram tanto as riquezas recém-descobertas quanto a expectativa de encontrar novas fontes de enriquecimento que motivaram a metrópole a exercer mais efetivamente seu poder sobre o território americano.

Podemos notar que a balança historiográfica tem pendido exageradamente para o papel das bandeiras paulistas e suas iniciativas privadas no processo de expansão dos domínios portugueses na América, enquanto têm sido quase relegados à nulidade os esforços metropolitanos que contribuíram para o mesmo fim. É conveniente, portanto, aquilatar com maior precisão o papel da metrópole nesse processo. Portugal obteve grandes benefícios territoriais, em detrimento da Espanha, através da assinatura do Tratado de Madri de 1750, pelo qual ficou estabelecido o princípio do "uti possidetis" como norteador da delimitação das fronteiras luso-castelhanas na América. Segundo este preceito, cada parte permaneceria com as porções que já haviam efetivamente ocupado. Assim, o anacrônico Tratado de Tordesilhas perdia definitivamente o seu valor político, passando Portugal a possuir legitimamente grandes porções territoriais além da antiga linha imaginária.

Desse modo, podemos logicamente supor que houve uma política de ocupação - ainda que apresentada de forma difusa na documentação analisada -, pois as riquezas encontradas na América no período, e a expectativa de encontrar mais, justificam uma atenção especial da metrópole nessa região do Império português. As possessões portuguesas na América constituíamse ainda no início do século XVIII um mundo a ser explorado. Isso não significa apenas que havia vastas regiões territoriais desconhecidas, mas sobretudo que esse Novo Mundo possuía grandes potencialidades econômicas que poderiam proporcionar grandes fontes de enriquecimento ao Reino. Nessa conjuntura, supomos que Portugal buscava incessantemente novas fontes de riquezas na América, com o intuito de fortalecer economicamente a monarquia.

Analisando o caso da capitania de São Paulo, durante o governo de Rodrigo César de Menezes, vemos que o processo de 
dilatação das fronteiras não pode, em vista da documentação consultada, ser considerado como um fenômeno totalmente espontâneo. Houve um claro interesse metropolitano na efetiva incorporação das recém-descobertas minas de Cuiabá e Goiás aos domínios portugueses, e um conjunto de ordens régias foi elaborado para proporcionar uma ocupação organizada.

Bastante ilustrativa a esse respeito é a carta do capitão Rodrigo César de Menezes ao Vice-Rei do Estado do Brasil escrita em abril de 1722, na qual o governador apresenta resumidamente as principais circunstâncias relativas ao seu governo na capitania até então (Documentos Interessantes, 1896, p. 19-25). Primeiramente, o governador apresenta o interesse da metrópole pelas riquezas que poderiam proporcionar as minas de Cuiabá. O governador também já dá mostras da maneira como pretende estabelecer a governabilidade metropolitana sobre a região cuiabana. Tudo deveria ser feito com "algum temperilho" para evitar revoltas contra o peso da presença do Estado português. A expressão "temperilho" descreve perfeitamente as intenções da metrópole sobre a região, interessada em estabelecer o governo sem que os moradores o sentissem com uma intensidade indesejável. Afirma o governador que:

Do novo descobrimento das minas de Cuiabá tem sido repetidas as notícias, e todas são gostosas. A última me veio por um homem de capacidade e inteligência, que gastou setenta dias na jornada, fazendo-a fora de monção, por ser o tempo da maior força das águas. Depõe ser a abundância do ouro muita, sem embargo de não haverem faiscado em forma até o natal, por se empregarem primeiro em plantar mantimentos, fazendo roças, como também em conquistarem o gentio, que não tem sido pouco [...] O povo elegeu por guarda-mor a Pascoal Moreira Cabral, que havia sido o descobridor, e por capitão-mor, para os governar, Fernando Dias Falcão, ambos sujeitos de capacidade [...] Eu me conformei com a eleição por ora, assim por entender estava bem feita, como por ser necessário levar 
|184|

Rodrigo César de Menezes e o papel da metrópole na ...

aquela gente com algum temperilho, porque em semelhantes ocasiões é o que mais vence. (p. 2- 21)

Rodrigo César de Menezes também já apresenta a sua preocupação com o abastecimento daquela região, através dos projetos acerca da abertura de um caminho. Logo após, descreve resumidamente o seu intento de passar às minas de Cuiabá, para estabelecer com mais firmeza a governança portuguesa na região. Literalmente, o capitão-general afirma que:
A 25 de abril se principiou a abrir o caminho novo, que ajustei se abrisse, como já dei conta à Vossa Excelência, e segura o homem dá-lo acabado nos fins de agosto, capaz de irem boiadas e cavalgaduras com cargas. [...] Assim os homens principais de toda esta capitania, como os que assistem em Cuiabá, procuram com grande instância que eu passe àquele novo descobrimento, porque de outra sorte é muito dificultoso conservarem-se unidos, como também para a boa arrecadação dos quintos reais. (p. 21- 23)

Esse interesse dos paulistas pela residência de Rodrigo César de Menezes em Cuiabá pode estar relacionado ao fato de que a presença de um capitão-general na região proporcionaria uma defesa considerável contra os perigos relacionados aos ataques dos índios belicosos e à proximidade dos castelhanos. Por fim, o governador apresenta a força das mercês para que a metrópole atingisse seus objetivos para a região. Ele informa ao Vice-Rei que "estes homens estimam mais a honra de um hábito de que toda outra conveniência". Em seguida, recomenda que "parece deve Sua Majestade, que Deus guarde, contentá-los com estas mercês [...] e posso assegurar a Vossa Excelência lhe deve o maior cuidado esta mercê". (p. 24)

Desse modo, essa carta do governador ao representante maior da metrópole no Estado do Brasil nos parece valiosíssima para comprovar a existência de toda uma gama de atitudes metropolitanas para com a região do novo descobrimento de 
Cuiabá. Essa correspondência apresenta de modo resumido os principais instrumentos utilizados pela metrópole no processo de anexação daquele espaço à capitania de São Paulo: o aumento da governabilidade, o abastecimento interno e a política de mercês. De modo geral, foram esses instrumentos que, elaborados pelo poder metropolitano, proporcionaram, juntamente com a iniciativa sertanistas, a efetiva integração daquele espaço à América portuguesa. Além disso, estes mesmos instrumentos foram utilizados, em diferentes proporções, nos sertões dos Guaiases, bem como nas demais regiões da capitania que se desejava conservar.

A utilização destes instrumentos pela metrópole, no processo de dilatação das fronteiras da capitania de São Paulo, é o que estamos denominando "política de ocupação". Como já foi apontado, é preciso deixar bem claro que, apesar da existência dessas diretrizes metropolitanas no tocante à ocupação sistematizada do território da capitania, essa política não está organizada em uma espécie de tratado e nem explicitamente ordenada em algum papel. De forma diferente, encontra-se difusa em toda a documentação correspondente à administração de Rodrigo César de Menezes na capitania de São Paulo. Por este motivo, é necessário analisar cuidadosamente o conteúdo de toda a documentação selecionada e organizá-la de modo que se possa visualizar as diretrizes dessa política.

A grande distância existente entre São Paulo, Cuiabá e Lisboa, motivo pelo qual se tornava dificultosa a comunicação entre o governo local e o central, fazia com que as diretrizes da política portuguesa em relação à ocupação do território não emanasse de um centro específico de poder, mas fosse elaborada e posta em prática pelas diferentes instâncias da organização estatal do Império. Desse modo, tanto os agentes metropolitanos residentes na América, como os membros do Conselho Ultramarino e o próprio monarca, tinham papel ativo nas decisões concernentes aos instrumentos utilizados para a dilatação das fronteiras da América portuguesa. 
| 186 |

Rodrigo César de Menezes e o papel da metrópole na ...

O aumento da governabilidade, a política de mercês e o abastecimento interno são os três grandes instrumentos utilizados pela metrópole para proporcionar efetivamente a incorporação das minas de Cuiabá e Goiás à América portuguesa e, portanto, na dilatação das fronteiras da capitania. Sobre essas duas regiões, o interesse metropolitano aparece na documentação com bastante intensidade. Em relação às minas de Cuiabá, Rodrigo César de Menezes afirmava em outra carta ao Vice-Rei, datada de 24 de dezembro de 1722, que "das esperanças das novas minas de Cuiabá me chegaram confirmadas não só de serem permanentes, mas abundantes de ouro e grande a sua extensão, e [...] esta notícia não pode causar pequeno gosto a Sua Majestade" (Documentos Interessantes, 1986, p. 35).

Em outra correspondência, ainda de modo mais claro o governador demonstra a sua ação sobre a região cuiabana, apresentando desde já os objetivos metropolitanos na incorporação daquele espaço ao seu domínio:

$$
\begin{aligned}
& \text { [...] e porque o descobrimento das novas minas do } \\
& \text { Cuiabá se acha com muitos mineiros e várias } \\
& \text { pessoas que tem concorrido para elas com grande } \\
& \text { número de escravos, e pelas notícias que tem dado } \\
& \text { muitas pessoas principais desta capitania que dela } \\
& \text { tem vindo, se tem a certeza de que a sua extensão é } \\
& \text { grande e que são permanentes, por cujas razões } \\
& \text { tenho procurado por todos os meios não só a sua } \\
& \text { subsistência, mas o seu grande aumento de dízimos } \\
& \text { e quintos reais. (Documentos Interessantes, 1901, } \\
& \text { p. 99). }
\end{aligned}
$$

Como já estavam descobertas as minas de Cuiabá desde antes do governo de Rodrigo César de Menezes, a política metropolitana para a região era direcionada para que uma organização fiscal fosse estruturada, visando o aumento da Fazenda Real. No caso dos sertões dos Guaiases, a metrópole agia em harmonia com a iniciativa bandeirante para proporcionar o descobrimento de ouro na região. Isso pode ser verificado pelo 
regimento elaborado pelo governo de Rodrigo César de Menezes, entregue ao célebre sertanista Bartolomeu Bueno da Silva, o segundo Anhanguera. Este documento estabelecia os fundamentos do contrato firmado entre eles e demonstra a existência de uma ação conjunta entre metrópole e paulistas no descobrimento. Na introdução do documento, o governador afirma que:

\footnotetext{
Porquanto Sua Majestade, que Deus guarde, foi servido ordenar-me por carta de 14 de fevereiro do ano passado de 1721, assinada pela sua mão real, ajustasse com o Capitão Bartolomeu Bueno da Silva o prêmio que se lhe havia de dar, no caso em que descobrisse nos sertões desta capitania minas de ouro e prata, e outros haveres, e que lhe desse regimento quando entrasse em tropa a fazer descobrimento nos ditos sertões, e em cumprimento da ordem do dito Senhor, lhe mandei dar o presente regimento, que há de guardar inviolavelmente o dito Capitão Bartolomeu Bueno da Silva. (Documentos Interessantes, 1901, p. 53).
}

Pode-se ver, dessa maneira, a inequívoca existência de firmes diretrizes estabelecidas pela metrópole no tocante à dilatação dos seus domínios, através dos descobrimentos auríferos nos sertões da América. Fica evidente que, além de uma política de ocupação que visava estabelecer a governança lusitana sobre as regiões já descobertas, como Cuiabá, a metrópole também agiu no sentido de promover, em uma espécie de aliança com os paulistas, novos descobrimentos auríferos. Baseados nessas convicções, estamos persuadidos de que a historiografia brasileira se equivocou quando afirmou que a incorporação desses espaços à América portuguesa foram feitos sem um auxílio significativo da Coroa lusitana. Esse equívoco está ligado à conviç̧ão de que a dilatação das fronteiras da América portuguesa se fez somente com a exploração do território pelas bandeiras, o que na verdade consiste apenas em um primeiro passo. Foi necessário, além disso, que 
| 188 |

Rodrigo César de Menezes e o papel da metrópole na ...

a metrópole dilatasse os seus domínios através de diversos instrumentos.

É muito importante assinalar que, no início do século XVIII, o império português já não era a grande potência que fora no século XVI. Com o Tratado de Methuen em 1703, Portugal tornara-se subordinado economicamente à Inglaterra. Sabe-se que toda a riqueza mineral extraída da América não fora suficiente para restaurar as glórias passadas do reino lusitano e fazê-lo reviver como o grande império de outrora. Apesar de todos os seus esforços, era um reino em decadência. Por esse motivo, é sensato supor que a política de expansão dos domínios portugueses na América esteja diretamente vinculada à tentativa de D. João $\mathrm{V}$ de reerguer economicamente o império, pelejando sempre pelo aumento da Fazenda Real, através de diversos instrumentos utilizados em suas possessões ultramarinas.

Quanto à região das minas de Cuiabá, era urgente que a metrópole elaborasse uma política de ocupação se desejasse auferir lucros consideráveis com aquele descobrimento. Isso porque a distância entre Cuiabá e as possessões castelhanas era relativamente pequena, e a Coroa temia perder a região para os espanhóis. Depois de informado sobre o assunto, Rodrigo César de Menezes afirmava o seguinte:

Eu tenho procurado examinar de todos estes homens práticos e dos melhores sertanistas a distância em que ficam as novas minas do Cuiabá à primeira povoação dos castelhanos, e todos uniformemente assentam que serão três meses de viagem, que além de dificultoso chegarem a eles pela aspereza do terreno, os impossibilita também a falta de água, porque os paulistas, por aquelas partes, dizem que, para satisfazerem a sede, se valiam da raiz de um pau, que metiam na boca, e pelo que a todos ouço, os respeitam os castelhanos, de sorte que basta ouvir o nome de paulista, a quem eles intitulam por feras, para não intentarem nenhum projeto, e a experiência bem tem mostrado foram estes sempre o seu flagelo. (Documentos Interessantes, 1896, p. 25) 
Apesar dessa aparente tranquilidade sobre o assunto, após averiguada a real distância entre as possessões portuguesas e castelhanas, além da fama dos paulistas para com eles, ainda era preciso temer o fato de que os próprio sertanistas podiam se submeter à Coroa espanhola, se achassem que isso seria mais proveitoso. Por esse motivo, era necessário que a metrópole elaborasse uma maneira de estender a sua governabilidade à região, respeitando o quanto possível a autonomia paulista, sem que os sertanistas se sentissem ultrajados. Após julgar ter tido bom êxito nesse propósito, Rodrigo César de Menezes informava ao Vice-Rei, em carta datada de janeiro de 1723, que:

Não tem sido pequena felicidade chegar a por as coisas nos termos em que estão, depois de achar tudo desordenado, parecendo não aproveitaria remédio algum, porque o ânimo destes homens estava bastantemente empedernido, concorrendo o seu avesso gênio para lho fazer endurecer mais, e os que se acham no novo descobrimento lhe excediam, pois publicavam que ainda tinham as feridas frescas do que nas Minas Gerais experimentaram, porque havendo sido os descobridores, foram os que sem honra nem riqueza ficaram, e porque assim não consentiriam passasse àquelas minas ninguém, alargando-se alguns a mais, dizendo que se os apertassem, dariam obediência a quem lhes atendesse, pois até aqui o não haviam devido a Sua Majestade, e como se não acham em muita distância dos castelhanos, se fazia este particular bastantemente vidrento. (Documentos Interessantes, 1986, p. 35-36).

Ademais, a concessão de sesmarias pode ser também compreendida, assim como a política de mercês e o aumento da governabilidade, como um dos instrumentos utilizados pela metrópole no processo de dilatação das fronteiras da capitania. As terras concedidas por sesmarias eram recompensas (mercês) oferecidas pela metrópole àqueles que se harmonizassem com o 
|190 |

Rodrigo César de Menezes e o papel da metrópole na ...

"serviço real de Sua Majestade". Por esse motivo, encontramos claramente em cada uma das cartas que o suplicante "pedia the fizesse mercê conceder, em nome de Sua Majestade, que Deus guarde, por carta de data de terra de sesmaria, as ditas terras" (Sesmarias, 1937).

Embora houvesse uma espontaneidade no afluxo populacional aos sertões auríferos da capitania, graças às riquezas prometidas pelos descobrimentos, a metrópole obrou no sentido de organizar essa ocupação, de modo que houvesse governo e rendimento em Cuiabá, e as fronteiras de fato se dilatassem. Nessa ocupação organizada, visada pela metrópole para que cada região proporcionasse os lucros esperados, o abastecimento interno era primordial. Caso não fossem bem estruturados os caminhos para os sertões e as produções agropecuárias, destinados ao abastecimento das regiões mineradoras, não haveria "combustível" para o funcionamento do sistema. Após a experiência de carestia nos primeiros anos da exploração aurífera em Minas Gerais, o capitão-general Rodrigo César de Menezes estava consciente da gravidade do problema. Por isso, se expressava da seguinte maneira em carta ao Vice-Rei do Brasil:

Pela abertura do novo caminho que fez o sargento-mor Luís Pedroso, pretendo fazer com que se introduza gado e cavalgaduras por ele nas ditas minas [de Cuiabá], e para se facilitar mais a passagem e vencer uma grande parte de distância, me foi preciso eleger um cabo dos melhores sertanistas, para que com um corpo de gente vá assistir naquela paragem que for mais conveniente [...] para que sem impedimento possam os viandantes cursar o caminho, com a introdução do gado e socorro de gente, que se faz muito necessário. (Documentos Interessantes, 1986, p. 211).

As sesmarias concedidas na capitania de São Paulo durante o governo de Rodrigo César de Menezes demonstram a estratégia metropolitana para o abastecimento interno das regiões produtivas da América portuguesa, sobretudo as regiões auríferas 
de Cuiabá e Minas Gerais, para que estas pudessem cumprir eficientemente o seu papel enquanto possessão da Coroa portuguesa. As cartas de sesmarias do período apresentam as diretrizes da metrópole relativas à produção agropecuária na capitania, voltadas acima de tudo para o aumento da Fazenda Real.

Como já foi explicitado, além de uma política de ocupação sobre as regiões economicamente favoráveis que se desejava anexar aos domínios lusitanos, havia também uma preocupação com as regiões da capitania mais vulneráveis aos ataques estrangeiros. A política de ocupação, desse modo, também caminhava no sentido de estabelecer uma melhor defesa militar sobre áreas que, embora já estivessem estabelecidas, precisam de uma atenção especial com relação aos adversários. Em carta régia enviada ao governador da capitania de São Paulo, o Conselho Ultramarino apontava as diretrizes sugeridas por Rodrigo César de Menezes no tocante à defesa do porto de Santos:

\begin{abstract}
Faço saber a vós Rodrigo César de Menezes, governador e capitão-general da capitania de São Paulo, que se viu o que me representastes em carta de vinte de dezembro do ano passado, em como as dependências desse governo crescem, aumentando-se juntamente às utilidades a minha Fazenda Real, e que pelo tempo em diante serão muito maiores, pelo prometer assim o que a experiência vai mostrando, e se vos fazia preciso fazer-me presente ser muito conveniente reforçar a guarnição do presídio de Santos com mais uma companhia de infantaria, para segurar aquele porto de qualquer invasão dos inimigos, por que daqui por diante poderão intentar invadi-la, pelas notícias do cabedal que a ele vai das novas minas de Cuiabá. (Documentos Interessantes, 1896, p. $144-145$ ).
\end{abstract}

Desse modo, fica bem clara a existência de uma política de ocupação do território da capitania de São Paulo, durante o governo de Rodrigo César de Menezes. As diretrizes dessa política 
| 192 |

Rodrigo César de Menezes e o papel da metrópole na ...

de ocupação estavam voltadas não somente para o aumento da governabilidade sobre as regiões que se desejava anexar, mas também ao incentivo a novos descobrimentos auríferos, à organização do abastecimento interno e à proteção de espaços já conquistados.

Tendo em vista, por fim, nossa hipótese inicial, podemos concluir que a metrópole exerceu um papel significativo no processo de incorporação das minas de Cuiabá aos domínios portugueses, contribuindo, dessa forma, para a dilatação das fronteiras da capitania de São Paulo. Cumpre-nos apontar, todavia, que a existência da ação metropolitana nesse processo não desmerece a ação sertanista - fator importantíssimo e também crucial para a realização da expansão territorial luso-americana - mas apenas equilibra com mais precisão a historiografia, sobretudo a paulista, que heroificou demasiadamente os sertanistas, tornando nula a participação da Coroa. Antes, demonstramos que houve, na realidade, uma confluência de interesses entre a metrópole e os poderosos paulistas - ou, em outras palavras, entre iniciativa pública e privada - na exploração de uma região economicamente atrativa, a qual foi anexada aos domínios portugueses através de uma ação conjunta.

Essa conclusão é valiosa na medida em que contribui para desmistificar a artificial oposição metrópole/colônia construída após a independência, demonstrando que, no processo de dilatação das fronteiras da capitania de São Paulo, houve uma harmonização entre o centro e a periferia, cada parte visando interesses específicos. Por outro lado, compreendemos também que a metrópole não elaborou uma política que visava exatamente a dilatação das fronteiras territoriais da América portuguesa, e nem os sertanistas buscavam a formação de um território nacional. Sucedeu que, labutando ambos incessantemente por interesses próprios - e por vezes unindo-se para alcançá-los -, a dilatação 
das fronteiras ocorreu como consequência, e não como objetivo. Em outros termos, a metrópole desempenhou sim um papel fundamental na expansão das fronteiras luso-americanas além Tordesilhas, embora seu objetivo não fosse exatamente dominar um colônia territorialmente imensa, mas imensamente rentável.

O estabelecimento da governabilidade nos sertões objetivava principalmente, portanto, o aumento da Fazenda Real, e não do território. Evidentemente, porém, um fator dependia do outro. Do mesmo modo, os sertanistas partiam aos sertões em busca de indígenas para escravizar ou de jazidas de metais preciosos, visando também a recompensa oferecida por Sua Majestade aos que descobrissem minas. Em suma, nem os sertanistas e nem a Coroa labutavam pelo aumento de território em si, mas por objetivos mais imediatos, centralizados no enriquecimento advindo da exploração aurífera. E mesmo o Tratado de Madri de 1750 parece estar centralizado na idéia de pacificação das conquistas portuguesas e castelhanas, através do estabelecimento de limites reconhecíveis, para a continuação dos lucros, e não com a noção de aumento territorial. Assim, metrópole e colonos agiram naquele contexto de acordo com o que sua própria época lhes apresentava - como não poderia deixar de ser -, e não a favor de interesses que eles nem mesmo conheciam, como a formação do território nacional brasileiro, o qual, todavia, acabaram inconscientemente colaborando para construir.

\section{Bibliografia}

CANAVARROS, Otávio. O poder metropolitano em Cuiabá (1727 - 1752). Cuiabá: UFMT, 2004.

HOLANDA, Sérgio Buarque de. Raízes do Brasil. 2. ed. Rio de Janeiro: José Olympio Editora, 1956.

JESUS, Nauk Maria de. Na trama dos conflitos: a administração na fronteira oeste da América portuguesa $(1719$ - 1778), Tese de Doutorado em História, UFF, Niterói, 2006. 
| 194 |

Rodrigo César de Menezes e o papel da metrópole na ...

LUIS, Washington. Capitania de São Paulo: governo de Rodrigo Cezar de Menezes. São Paulo: Typ. Casa Garrauz, 1918

MAGALHÃES, Basílio de. Expansão geográfica do Brasil Colonial. 4. ed. São Paulo: Nacional, 1978.

OLIVAL, Fernanda. As Ordens Militares e o Estado Moderno: honra, mercê e venalidade em Portugal (1641-1789), Lisboa: Estar, 2001.

PAES LEME, Pedro Taques de Almeida. Nobiliarquia paulistanae genealógica, 3 vols. 5 ed. Belo Horizonte: Itatiaia; São Paulo: EDUSP, 1980.

SOUZA, Laura de Mello e. "Morrer em colônias: Rodrigo César de Menezes, entre o mar e o sertão" In. O sol e a sombra: política e administração na América portuguesa do século XVIII. São Paulo: Companhia de Letras, 2006, p. 284-326.

TAUNAY, Affonso. História das Bandeiras Paulistas, 3 vols. 3. ed. São Paulo: Melhoramentos, 1975.

VOLPATO, Luiza Rios Ricci. A conquista da terra no universo da pobreza: formação da fronteira oeste do Brasil, 1719-1819. São Paulo, HUCITEC; Brasília, INL, 1987.

\section{Fontes}

"Decreto Real de 1643" apud CAETANO, Marcelo. O conselho ultramarino: esboço de sua história. Lisboa: Agência-geral do ultramar, 1967, p. 125.

"Registro de uma carta escrita ao Vice-Rei do Estado" In. Arquivo do Estado de São Paulo. Documentos Interessantes, v. XX. São Paulo: Typographia Aurora, 1896, p. 19-24.

"Para o Senhor Vice-Rei" In Arquivo do Estado de São Paulo. Documentos Interessantes, v. XX. São Paulo: Typographia Aurora, 1896, p. 35.

"Registro do regimento que levou para as novas minas de Cuiabá o mestre de campo regente João Leme da Silva" In Arquivo do Estado de São Paulo. Documentos Interessantes, v. XII. São Paulo: Escola Typographica Salesiana, 1901, p. 99. 
"Registro do regimento que levou o Capitão Bartolomeu Bueno da Silva, cabo da tropa que foi ao sertão a descobrir minas de ouro e pedras preciosas" In Arquivo do Estado de São Paulo. Documentos Interessantes, v. XII. São Paulo: Escola Typographica Salesiana, 1901, p. 53.

"Registro de outra carta para o dito Senhor Vice-Rei" In Arquivo do Estado de São Paulo. Documentos Interessantes, v. XX. São Paulo: Typographia Aurora, 1896, p. 25.

“Para o Senhor Vice-Rei” In Arquivo do Estado de São Paulo. Documentos Interessantes, v. XX. São Paulo: Typographia Aurora, 1896, p. $35-36$.

Arquivo do Estado de São Paulo. Sesmarias (1720 - 1736), v. III. Edição do Instituto Histórico e Geográfico de São Paulo, 1937.

"Registro de uma carta escrita ao Excelentíssimo Senhor Vice-Rei do Estado" In Arquivo do Estado de São Paulo. Documentos Interessantes, v. XX. São Paulo: Typographia Aurora, 1896, p. 211.

"Para o Senhor Vice-Rei" In Arquivo do Estado de São Paulo. Documentos Interessantes, v. XX. São Paulo: Typographia Aurora, 1896, p. 37.

"Registro de uma carta de data de terra de sesmaria, de légua e meia em quadra, de Luiz Rodrigues Vilares, do sítio Camapuã" In. Arquivo do Estado de São Paulo. Sesmarias (1720 - 1736). vol. III. Edição do Instituto Histórico e Geográfico de São Paulo, 1937, p. 169.

"Registro de uma carta que se escreveu ao general do Rio de Janeiro sobre a abertura do novo caminho" In Arquivo do Estado de São Paulo. Documentos Interessantes, v. XX. São Paulo: Typographia Aurora, 1896, p. 153.

“Carta régia participando que o rei de Portugal não concorda com as medidas propostas para a defesa do porto de Santos". In Arquivo do Estado deSão Paulo. Documentos Interessantes, v. XVIII. São Paulo: Typographia Aurora, 1896, p. 144-145. 